\title{
Aspectos da caça no alto rio Aripuanà
}

\author{
J. M. Ayres (") \\ Cristina Ayres $\left({ }^{*}\right)$
}

\section{Resumo}

Através de levantementos entre janeiro e abril de 1978, com toda o pcpulação de Dardanelos (Aripuanā-MT) a caça abatida na área foi determinada. As queixadas (Tayassu pecari), as antas (Tapirus terrestris) e os caititus (Tayassu tajacu) representa ram $89 \%$ dos $8857 \mathrm{~kg}$ de caça abatida neste período. A carne de caça representou uma importante fonte adicional de proteínas e estava presente em $19 \%$ das refeiçōes. Os principais métodos de caça na área são descritos e a necessidade de conservaçāo da fauna na regiāo discutida.

\section{INTRODUÇÃo}

Localizado ao sul da Amazônia, Aripuanā, com aproximadamente $140.000 \mathrm{~km}^{2}$ é o segundo município brasileiro em extensão territorial, e o de mais baixa densidade demográfica do Estado de Mato Grosso, com $0,02 \mathrm{hab} / \mathrm{km}^{2}$ (FIBGE, 1970).

A sede do município está situada a $10^{\circ} 10^{\prime} \mathrm{S}$ e $50^{\circ} 27^{\prime} \mathrm{W}$ (Fig. 1), numa altitude de 203 metros, à margem direita do rio Aripuanã nas proximidades do Salto de Dardanelos (130 metros de altura) e Salto das Andorinhas. Fica distante em linha reta cerca de $800 \mathrm{~km}$ norte de Cuiabá, a Capital do Estado. Até junho de 1978, época da chegada da Rodovia AR 01, que liga Aripuanã aos centros produtivos do Estado, Dardanelos era uma Vila cuja subsistência estava ligada principalmente ao plantio da mandioca, arroz, feijão e algumas atividades extrativas, como óleos vegetais (Copaifera sp.), seringa, caucho, castanha, pesca, caça e, mais recentemente, o garimpo de ouro do igarapé Ouro Preto, afluente do rio Branco.

Embora a floresta amazônica seja muito rica em relaçãc a sua fauna, a biomassa dos verfebrados é baixa (Fittkau \& Klinge, 1973) apesar de que para muitos grupos populacionais da região ela consista numa importante fonte de proteina animal (Pierret \& Dourojeanni, 1966 e 1967; Smith, 1976a) .

Traiamos no presente trabalho sobre a contribuição da caça na dieta da populaçăo de Dardanelos e sua importância no preenchimento das necessidades proteicas dos seus moradores. Investigamos sobre os métodos empregados para caçar e sobre a importância da conservação de seu recurso natural renovável para o desenvolvimento futuro da região.

\section{ÁreA de ESTUdos}

A primeira concentração de pessoas na localidade data do final do século XIX, pelos seringueiros do Norte e Nordeste e posteriormente pelos garimpeiros de ouro e diamantes (Arnaud \& Cortez, 1976). Em 1970 haviam apenas 80 habitantes em Dardanelos e um grande aumento na população ocorreu após a implantação do Núcleo Pioneiro de Humboldt em 1973. Em maio de 1978, por exemplo, haviam 638 habitantes em Aripuanã.

A vegetação é formada principalmente por matas primárias de terra firme. Esta região também é rica em igapós formados pelas áreas baixas próximas ao leito óos rios e que sofrem alagamento periódico destas águas, onde aparecem praias de areia branca (Pires, 1974). Nas vizinhanças de Dardanelos nota-se a presença de capoeiras em diversos estágios de sucessão vegetal. Até julho de 1978 as áreas derrubadas não ultrapassavam a $40 \mathrm{C}$ hectares.

O clima é tropical de monção, variedade Amg de acordo com a classificação de Köppen, caracterizado por um verão seco e inverno chuvoso, regime continental. A pre-

(") - Instituto Nacional de Pesquisas da Amazônia, Núcleo, Aripuanã. 


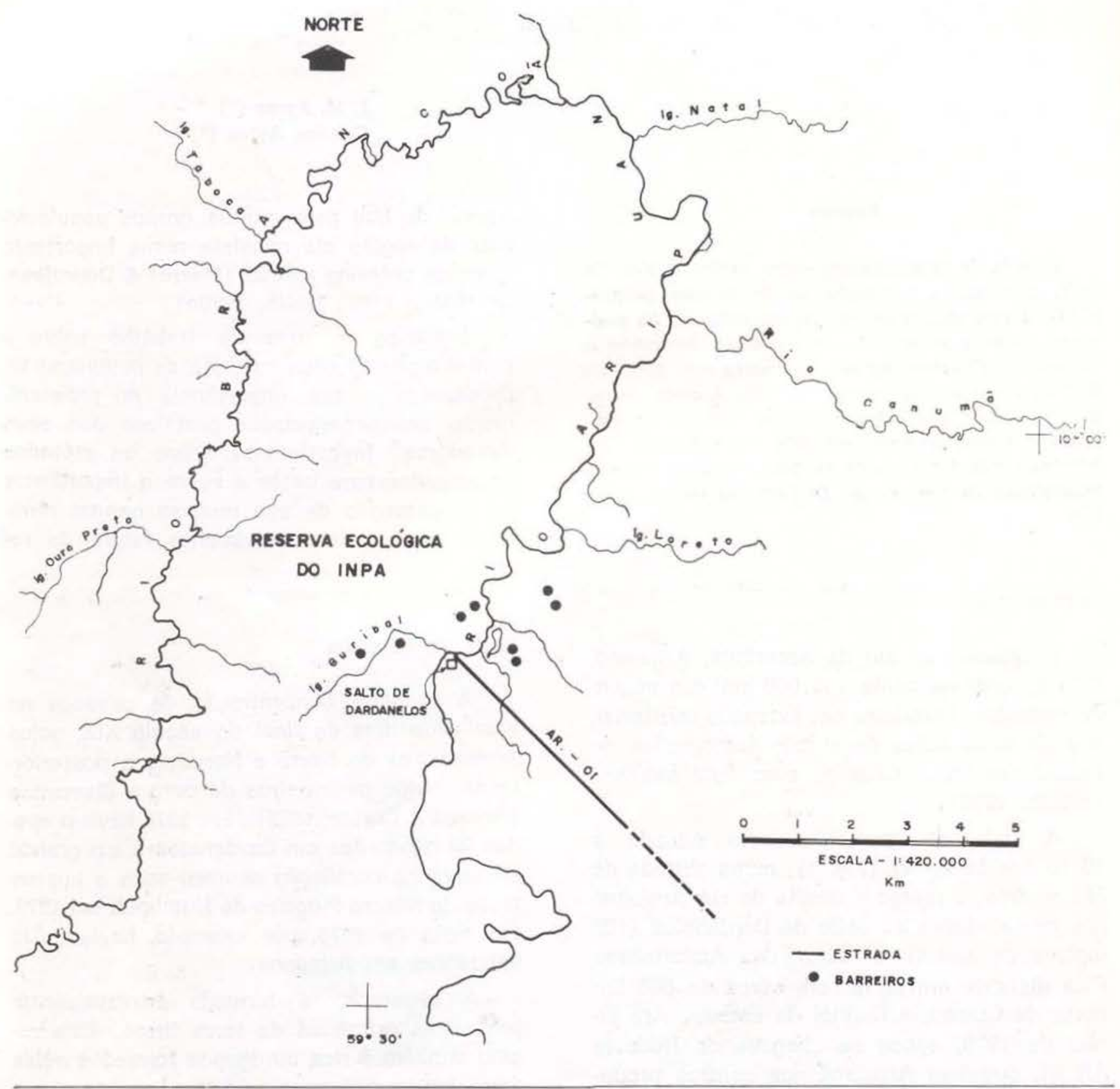

Fig. 1 - Area de estudo no Município de Aripuanã

cipitação média anual é de $2.100 \mathrm{~mm}$, cơm o o período seco pronunciado de abril até setembro. A temperatura média anual é de $25,5+1,5^{\circ} \mathrm{C}$.

\section{MÉTodos}

Entrevistamos toda a populaçäo da localidade, entre janeiro e abril de 1978. Acompanhamos os caçadores nas principais trilhas de caça que somam $110 \mathrm{~km}(\mathrm{n}=12)$, em maio e junho de 1977 e julho de 1978. Coletamos amostras dos barreiros mais próximos do povoado, fizemos observaçōes diretas na Reserva Ecológica do INPA, na margem do rio Aripuanã durante o curso de um estudo sobre a Ecologia e o Comportamento do Chiropotes albinasus.

Os pesos dos animais maiores, foram em sua maioria estimados com relativa precisão 
pelos caçadores, pois estes vendem a carne no local. Os pesos dos animais menores, quando houve dúvida por parte do caçador, foram tomados da literatura (Napier \& Napier. 1967; Novaes, 1976).

A maneira com que os dados foram coletados provavelmente favorece os animais de maior porte como a anta (Tapirus terrestris). a queixada (Tayassu pecari) e o veado capoeira (Mazama sp.) (Tabela 1). Também há uma tendência de não aparecerem animais comercializados pelo couro como a onça pintada (Panthera onca), jaguatirica (Felis pardalis), o gato maracajá (Felis wiedii), a lontra (Lutra sp.) e a ariranha (Pteronura brasiliensis). devido a lei $n^{\circ} 5197$ (do IBDF), que proibe a captura de animais silvestres para a comercialização de peles, a partir de 1967.
Isto não significa que estes animais não sejam abatidos, pois durante o curso do estudo foram localizadas várias armadilhas de construção recente pelo "gateiros" da região

\section{RESULtados}

A população de Dardanelos em maio de 1978 era de 638 habitantes (Fig. 2) distribuida em 114 grupos domésticos com uma média de $5,6 \pm 3,2$ indivíduos por família. Encontramos nessa população 33 pessoas que se dedicam tanto à caça como à pesca, 19 pessoas que somente pescam e 9 que somente caçam.

Durante $\alpha$ mês de maio tomamos uma amostra de 1.276 refeições, o equivalente a 2 refeições por indivíduo da população total.

TABELA 1 - Relação dos animais abatidos nas vizinhanças do Salto de Dardanelos, de janeiro a abril de 1978.

\begin{tabular}{|c|c|c|c|c|c|}
\hline Nome local & Científico & Quantidade & $\begin{array}{c}\text { Paso total } \\
\text { (Kg) }\end{array}$ & $\begin{array}{l}\text { Peso médio } \\
(\mathrm{Kg})\end{array}$ & $\%$ \\
\hline Queixada, Porcão & - Tayassu pecari & 338 & 6084,0 & 18,00 & 68,69 \\
\hline Anta & - Tapirus terrestris & 9 & $y 90,0$ & 110,00 & 11,18 \\
\hline Caititu & Tayassu tajacu & 70 & 840,0 & 12,00 & 9,47 \\
\hline Veado capoeira & - Mazama sp. & 12 & 276,0 & 23,50 & 3,12 \\
\hline Macaco barrigudo & - Lagothrix lagothricha & 35 & 220,5 & 6,30 & 2,48 \\
\hline Mutum & + Mitu mitu & 40 & 128,0 & 3,20 & 1,45 \\
\hline Tatu de quinze quilos & Dasypus keppleri & 7 & 66,5 & 9.50 & 0.75 \\
\hline Jacu & + Penelope sp. & 33 & 66,0 & 2,00 & 0,75 \\
\hline Pato do mato & + Cairina moschata & 8 & 28.0 & 3,50 & 0,32 \\
\hline Onça Parda, Sussuarana & Felis concolor & 1 & 23,0 & 23,00 & 0,26 \\
\hline Cuxiú de Nariz branco & - Chiropotes albinasus & 8 & 22,4 & 2,80 & 0,25 \\
\hline Jacutinga, Cujubim & + Pipile cujubi & 6 & 19.2 & 3,20 & 0,22 \\
\hline Tatu galinha & - Dasypus novencinctus & 7 & 17,5 & 2,50 & 0,20 \\
\hline Cotia & - Dasyprocta sp. & 7 & 17,5 & 2,50 & 0,20 \\
\hline Arara & + Ara macao e Ara ararauna & 14 & 14,0 & 1,00 & 0,16 \\
\hline Paca & Agouti paca & 2 & 13,4 & 6,70 & 0,15 \\
\hline Jacamim & + Psophia viridis & 4 & 8.0 & 2.00 & 0,09 \\
\hline Tracajá & ** Podocnemis unifilis & 2 & 8,0 & 4,00 & 0,09 \\
\hline Carará & + Phalacrocorax olivaceus & 4 & 7,2 & 1,80 & 0.08 \\
\hline Coati & Nasua nasua & 1 & 3,0 & 3,00 & 0,03 \\
\hline Cairara & - Cebus albifrons & 1 & 2,7 & 2,70 & 0.03 \\
\hline Zogue zogue & - Callicebus moloch & 1 & 0.7 & 0,70 & \\
\hline Papagaio & + Amazona sp. & 1 & 0,5 & 0,50 & \\
\hline Jaboti lalá & $\therefore$ Platemys platicephala & 1 & 0,5 & 0.50 & 0,03 \\
\hline Sauím, Sagui & - Callithrix argentata & 1 & 0,4 & 0,40 & \\
\hline Socó & + Butorides striatus & 1 & 0,2 & 0,20 & \\
\hline TOTAL & - & 582 & 8857,2 & - & 100 \\
\hline
\end{tabular}




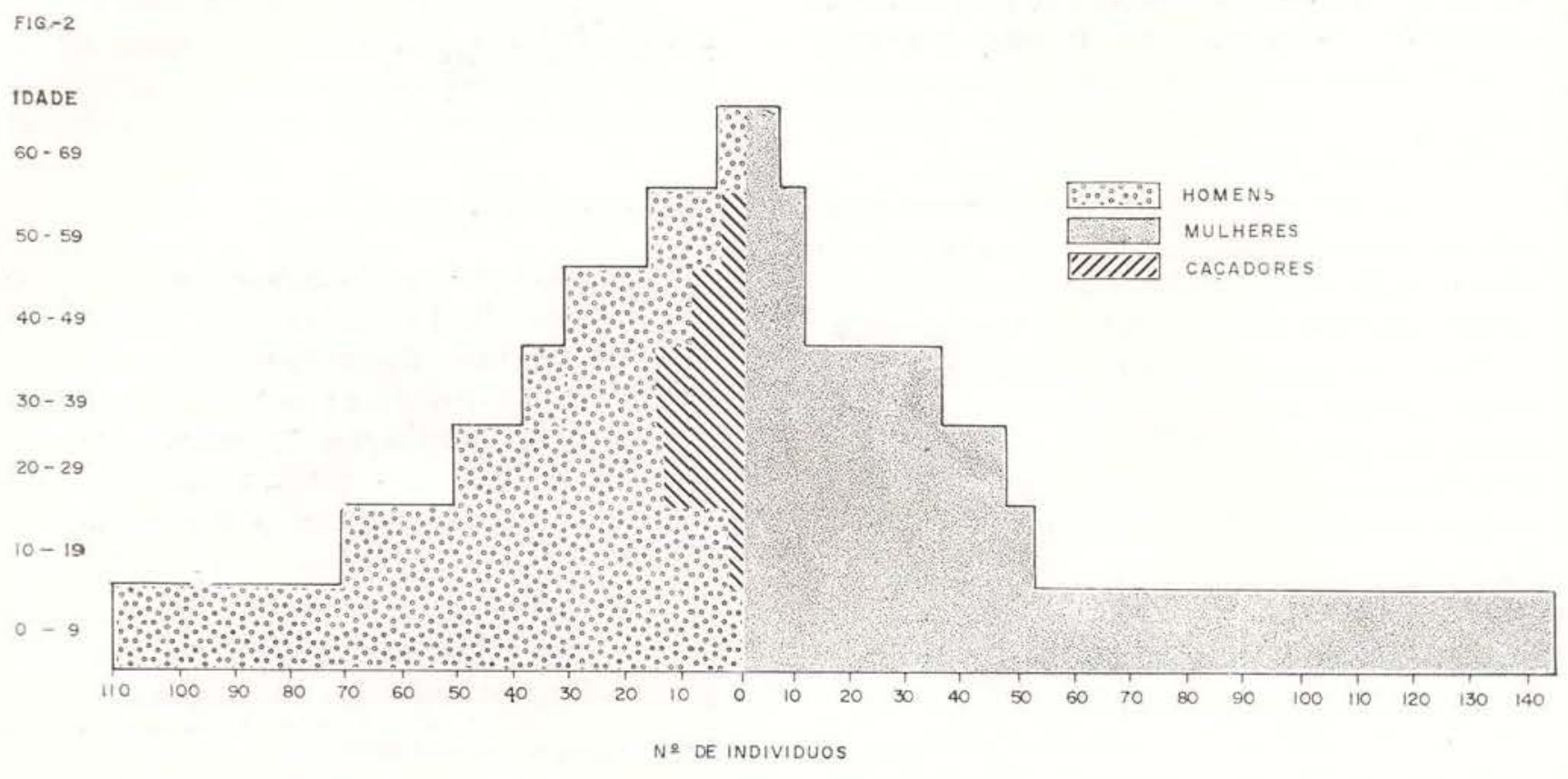

Fig. 2 - Distribuição da população de Aripuanã por sexo e idade.

O pescado estava presente em $13 \%$, a carne de caça em $20 \%$, conserva, charque, galinha e outros tipos de carne em $48 \%$, enquanto que $19 \%$ das refeições não continham nenhum tipo de carne (Fig. 3 e Tab. 2) .

A pesca no alto rio Aripuanã parece ter uma importância menor no fornecimento de proteína animal que a carne de gado, embora o nủmero de pessoas que se dedicam a esta atividade seja superior ao daquelas que caçam. As primeiras cachoeiras do rio Aripuanã nas vizinhanças de Sumaúma, próximo a fronteira dos Estados do Mato Grosso e Amazonas, funcionam como uma barreira geográfica para várias espécies da fauna aquática da Bacia Amazônica, como o pirarucu (Arapaima gigas), o pixe-boi (Trichechus inunguis), e os botos (Inia geoffrensis e Sotalia fluviatlis), que não conseguem ultrapassar estes obstáculos. Outra barreira é o próprio Salto de Dardanelos e Andorinhas; com 130 metros de altura, e que acima deles existem poucas espécies de peixes de valor econômico para a alimentação humana, como a traíra (Hoplias sp.) e o sapatăo (Trachycorystes sp.) (INPA. Setor Peixe e Pesca, 1976) .

O consumo de carne bovina é relativamente baixo devido ao fato de que não havia, na época, meios de comunicação com os centros de produção pecuária, tanto pela falta de estrada como pelas inúmeras cachoeiras que dificutlam o transporte fluvial, tornando o
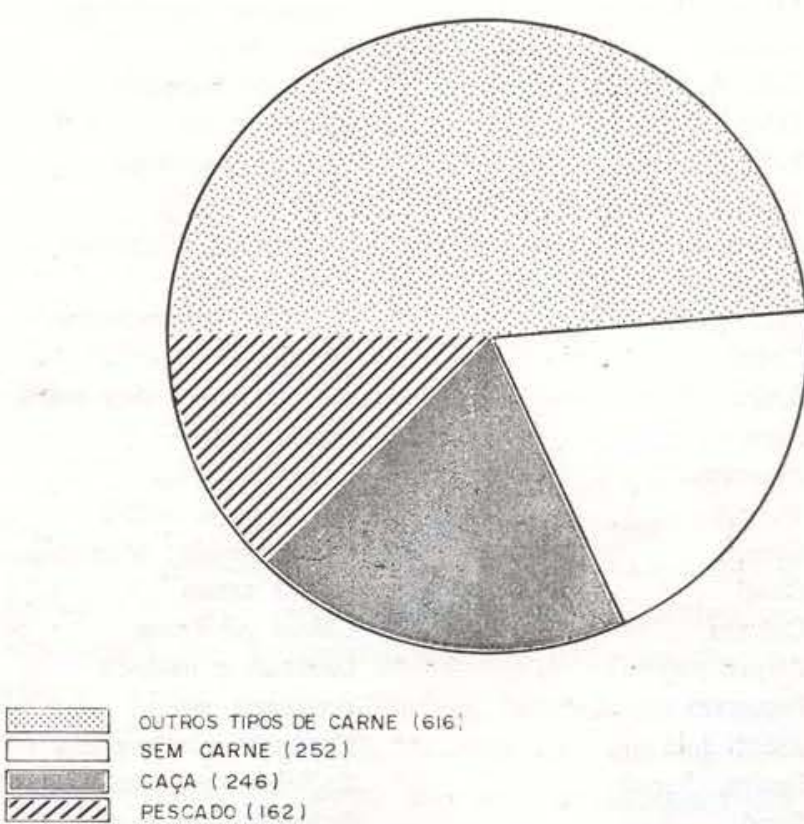

OUTROS TIPOS DE CARNE $(616$ : SEM CARNE (252)

CAÇA (246)

PESCADO (162)

Fig. 3-Consumo de diferentes tipos de carne em Aripuanã, maio/78 (1276 refeições). 
TABELA 2 - Consumo de diferentes tipos de carne em Dardanelos em um dia de maio de 1978 (2 refeiçōes por individuo).

\begin{tabular}{lrr}
\hline Tipo de Carne & Vezes citado & $\%$ \\
\hline Charque & 392 & 30,69 \\
Refeiçōes sem carne & 252 & 19,75 \\
Queixada & 173 & 13,52 \\
Peixe & 162 & 12,70 \\
Gado (fresca) & 144 & 11,32 \\
Galinha & 42 & 3,29 \\
Conserva & 38 & 3,01 \\
Anta & 26 & 2,04 \\
Veado & 24 & 1,88 \\
Caititu & 18 & 1,41 \\
Tatu & 5 & 0,39 \\
\hline T O TA L & 1276 & 100 \\
\hline
\end{tabular}

transporte aéreo bastante oneroso e fazendo com que a carne de gado atingisse um preço 2,5 vezes superior ao da carne de caça abatida nas vizinhanças. Sem levar em consideração as criações experimentais do INPA, haviam na comunidade em maio de 1978, 598 galinhas, 71 patos, 20 porcos e 2 perus.

\section{OS CAÇADORES}

A média de idade dos caçadores foi de $35,0 \pm 10,00$ anos, dos quais $80 \%$ são originários na Região Norte principalmente dos Estados do Acre e Amazonas (ric Roosevelt, baixo e médio rio Aripuanã). Os $11 \%$ de nordestinos que praticam a caça já estavam estabelecidos na região como seringueiros e garimpeiros a mais de uma década (Tab. 3). Apenas 4 caçadores saem para a mata mais de 2 vezes por semana e estes sâo responsáveis por quase que a metade do peso total $(8857 \mathrm{~kg})$ abatido durante os 120 dias do levantamento. Os caçadores que obtiveram peso na faixa de 0 a $299 \mathrm{~kg}$ (Tab. 4) preferem caçar somente aos sábados e domingos, o que pode ser uma decorrência da atividade que ocupa cada indivíduo durante a semana. Dos 60 empregados permanentes ou mensalistas da Vila, cuja a periođicidade média de trabalho é de 8 horas por dia, apenas 5 caçam. Dos 56 autônomos, isto é, comerciantes, agricultores, empreitei- ros, garimpeiros etc., 12 são caçadores, eñquanto que 27 dos 70 empregados temporários ou diaristas praticam essa atividade.

\section{MÉTODOS DE CAÇA}

Os caçadores que obtiveram pesos na faixa de 300 a $2.000 \mathrm{~kg}$ em animais abatidos (Tab. 4) preferem caçar sem o auxilio de um companheiro, exceto em caso que a caçada vai ser realizada muito distante do povoado. Esta tendência está aumentando muito nos últimos anos com a diminuição das populações animais das matas mais próximas à Vila, devido a destruição dos habitats naturais e a própria atividade da caça.

TABELA 3 - Origem dos caçadores e cia população de Dardanelos maio 1978

\begin{tabular}{|c|c|c|c|}
\hline \multirow[t]{2}{*}{$\begin{array}{l}\text { LOCAL DE } \\
\text { NASCIMENTO }\end{array}$} & \multicolumn{3}{|c|}{ QUANTIDADE } \\
\hline & $\begin{array}{l}\text { Absoluta } \\
\text { totol }\end{array}$ & $\%$ & $\begin{array}{l}\text { Absoluta } \\
\text { caşadores }\end{array}$ \\
\hline Vila de Dardanelos ... & 123 & 19.28 & - \\
\hline Município de Aripuanã & 96 & 15.05 & 12 \\
\hline Outros $\ldots . . . \ldots \ldots \ldots$ & 99 & 15,52 & 1 \\
\hline $\begin{array}{l}\text { Naturais do Mato Gros- } \\
\text { so (subtotal) } \ldots . . . \text {. }\end{array}$ & 318 & 49,85 & 13 \\
\hline Região Norte ........ & 231 & 36,21 & 23 \\
\hline Região Nordeste ...... & 44 & $6 ; 90$ & 5 \\
\hline Regiăo Leste ........ & 13 & 2,04 & 1 \\
\hline Região Sul .......... & 16 & 2.50 & 1 \\
\hline Outros $\ldots \ldots \ldots \ldots \ldots$ & 16 & 2,50 & 1 \\
\hline Näo naturais do Mato & & & \\
\hline Grosso (Subtotal) ... & 320 & 50.15 & 31 \\
\hline TOTAL & 638 & 100 & 44 \\
\hline
\end{tabular}

TABELA 4 - Desempenho (Kg-Caça) por grupo de caçadores.

\begin{tabular}{ccc}
\hline $\begin{array}{c}\text { Faixa de Peso } \\
(\mathrm{Kg})\end{array}$ & N.0 de caçadores & $\begin{array}{c}\% \\
(\text { Total }=8829 \mathrm{Kg})\end{array}$ \\
\hline $0-99$ & 27 & 12,26 \\
$100-299$ & 9 & 19,82 \\
$300-499$ & 4 & 20,17 \\
$500-999$ & 2 & 16,07 \\
$1000-2000$ & 2 & 31,32 \\
\hline T OT A L & 44 & 100 \\
\hline
\end{tabular}


Os cães não são muito utilizados para o auxílio nas caçadas, embora 49 caititus (Tayassu tajacu) foram abatidos com o auxílio de um cachorro por apenas 1 caçador, nos primeiros 120 dias de 1978.

A caça de espera é usada principalmente para mamíferos de hábitos noturnos, como a anta (Tapirus terrestris) e a paca (Agouti paca). É mais comum no verão, pois nesta época a caça de excursão torna-se difícil, com as folhas secas, aumentando assim o ruído quando o caçador caminha afugentando os animais mais próximos. Também porque durante as chuvas os barreiros estão parcialmente inundados.

Existem duas maneiras principais de esperar a caça: nos barreiros (Fig. 4) e nas árvores (Tab. 6). Os barreiros são locais de solo argiloso que ocorrem nas proximidades dos cursos d'água, com inundação periódica ou na terra firme, em menor número. Estudo recente (Weeks \& Kirpatrick, 1976) demons- tra que a procura dos herbivoros pelos barreiros é uma adaptação desses animais para as deficiências nutricionais de certos minerais principalmente do sódio.

Os resultados apresentados (Tab. 5) foram obtidos de amostras superficiais colhidas em 9 barreiros, 8 dos quais (Fig. 1) estão dentro da área de ação dos caçadores de Dardanelos. Estes resultados são preliminares e as análises de outros nutrientes estão em andamento.

Os resultados de carbono orgânico mostram tratar-se de áreas com relativamente pouca deposição orgânica e/ou de grande remoção desta. Como se observa os teores são bastantes inferiores ao conteúdo médio das terras da região. $\mathrm{O}$ pH é em média bastante superior aos que ocorrem na região e mostram tratar-se de materiais com predominân. cia de reações alcalinas. Observa-se que o aumento do $\mathrm{pH}$ se relaciona com os ions de $\mathrm{Ca}^{++}$e $\mathrm{Mg}^{++*}$ trocáveis.

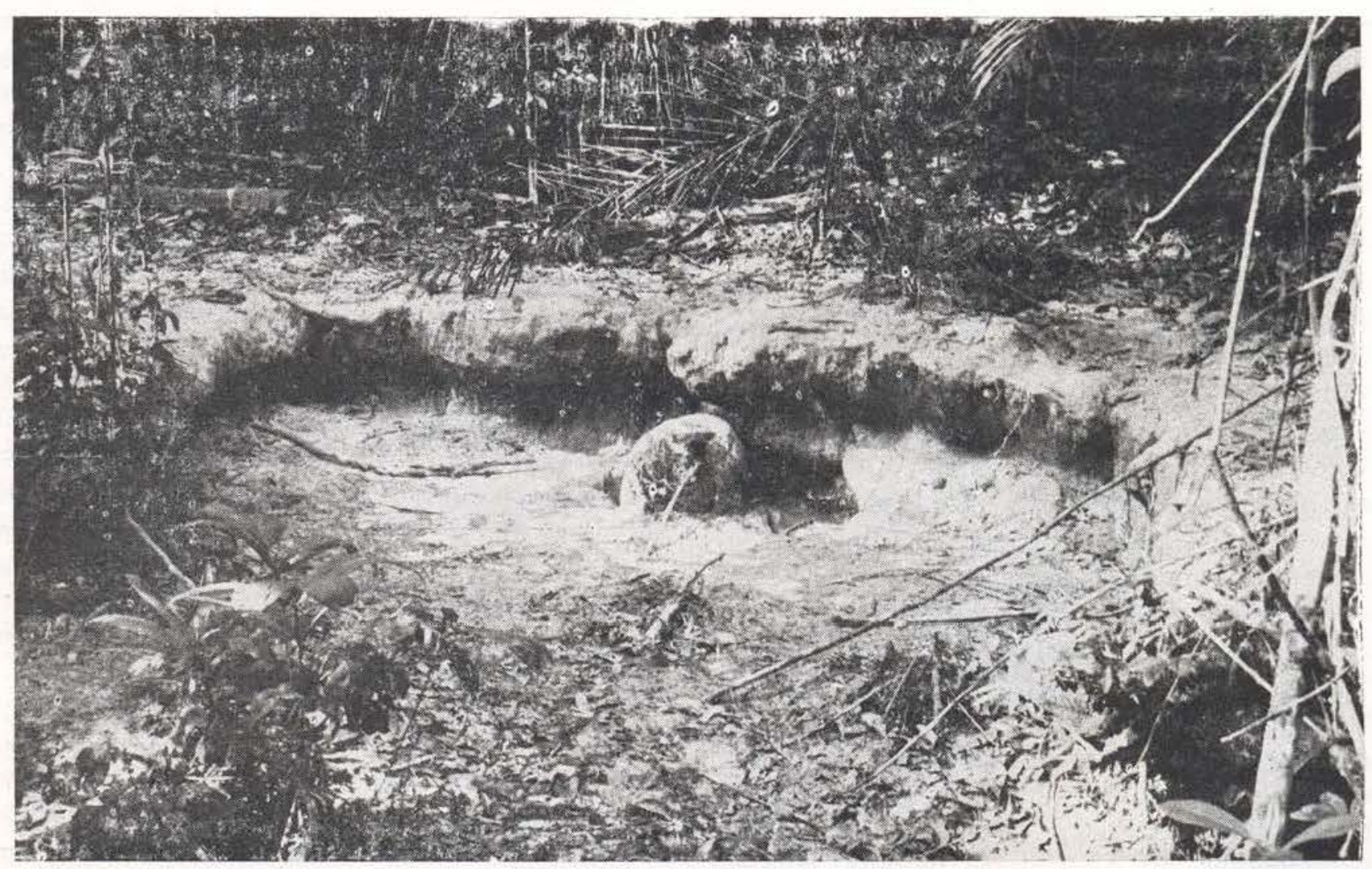

Fig. 4 - Aspecto geral do barreiro na Reserva Ecológica do INPA, muito utilizado na caça de espera peios moradores de Dardanelos. 
TABELA 5 - Resultados analíticos obtidos de amostras superficiais do solo colhidas em diversos barreiros.

\begin{tabular}{|c|c|c|c|c|c|c|c|c|c|}
\hline & & & & & $\mathrm{K}$ & $\mathrm{P}$ & $\mathrm{A} !+++$ & $\mathrm{Ca}_{++}^{+}$ & $\mathrm{Mg}++$ \\
\hline & 104 & & $\mathrm{PH}_{2} \mathrm{O}$ & & $\mathrm{mg} / \mathrm{ml}$ & T.F.S.A. & e. & $\mathrm{mg} / 100 \mathrm{ml}$ & T.F.S.A. \\
\hline Barreiro 1 & & 0.99 & 8.0 & & 36 & 3 & 0,00 & 4,2 & 0,5 \\
\hline Barreiro 2 & & 0,49 & 4,7 & & 20 & 1 & 5,75 & 0.4 & 0,8 \\
\hline Barreiro 3 & & 0,42 & 6,6 & & 56 & 1 & 0,41 & 1,8 & 1,3 \\
\hline Barreiro 4 & & 0,63 & 6,7 & & 32 & 2 & 0,00 & 3,2 & 1,8 \\
\hline Barroiro 5 & & 0,64 & 7,0 & & 32 & 1 & 0.00 & 4.2 & 3,6 \\
\hline Barreiro 6 & & 0,27 & 7,1 & & 32. & 5 & 0.11 & 0,7 & 2,8 \\
\hline Barreiro 7 & & 0,35 & 7.5 & & 36 & 4 & 0,00 & 9,9 & 1,8 \\
\hline Barreiro 8 & & 1,35 & 7,9 & & 24 & 5 & 0,00 & 6,0 & 1,6 \\
\hline Barreiro 9 & & 0.50 & 8,1 & & 32 & 7 & 0.00 & $\quad 5,2$ & 1,7 \\
\hline Barreiros & 0,63 & $3 \pm 0,34$ & $7,07 \pm\{, 05$ & 33,3 & $\pm 10,0$ & $3,2 \pm 2,2$ & $0,7 \pm 1,9$ & $3,9 \pm 3,0$ & $1.8 \pm 0,9$ \\
\hline $\begin{array}{l}\text { Outras amostras } \\
\qquad(n=18)\end{array}$ & 1,49 & $9 \pm 0.27$ & $5,64 \pm 0,41$ & 174,2 & $\pm 65,9$ & $7.6 \pm 8,2$ & $0.1 \pm 0.1$ & $3.8 \pm 2,0$ & $2.4 \pm 1.3$ \\
\hline
\end{tabular}

Nos barreiros freqüentam as queixadas (Tayassu pecari), os caititus (T. tajacu)***, a anta (Tapirus terrestris)", o veado (Mazama sp.) ${ }^{*}$, o coatá (Ateles paniscus) ${ }^{\cdots "}$, a guariba (Alouatta seniculus) $^{* * *}$, a paca (Agouti paca) ${ }^{* * *}$, o mutum (Mitu mitu $)^{* 2 *}$, o jacu (Penelope sp.) ${ }^{* *}$, o cujubim (Pipile cujubi) ${ }^{*}$ e muitas espécies de Psittacidae (Pyrrhura sp. e Pionopsitta sp.).**

Normalmente uma parte do barreiro ou nas proximidades a argila fica parcialmente umidecida o que permite ao caçador observar pelas pegadas que animais estão freqüentando aquele barreiro. Durante a chuva não é muito freqüente a espera nesses locais, porque a maioria está parcialmente inundada. Ao entardecer os caçadores atam suas redes ou constroem um pequeno jirau nas proximidades (2 a $3 \mathrm{~m}$ de altura) e ficam ali esperando com a lanterna e a cartucheira até a hora que o animal se aproxima. Em noites de luar, os caçadores não esperam a caça nos barreiros, pois informaram que os animais só vêm comer o barro em noites escuras.
Os barreiros constituem-se no ponto principal das caça de espera e de excursão diurna nas quais o caçador pode passar em 1 ou 2 barreiros, aumentando assim a sua chance de ser bem sucedido. Quando o barreiro é muito distante do povoado e/ou entre serras, eles preferem ir a dois para dividir o transporte da caça .

Algumas árvores, cujas flores e/ou frutos, em determinada época do ano, servem como alimento para diversas espécies de animais na área (Tab. 6) são usadas pelos caçadores para a espera. Entretanto, eles evitam caçar quando os animais estão se alimentando de frutos de plantas como a caferana (Picrolemma pseudocoffea) ou o mururé (Brosimum sp.) que alteram o sabor da carne, tornando-a amarga. O método de espera em árvore é também mais empregado na estaçăo seca e tem uma menor importância pela existência de barreiros na região.

As armadilhas para captura do gato maracajá (Felis wiedii) e jaguatirica (Felis pardalis) seguem o modelo porta que fecha como guilhotina, descrito por Smith (1976b), cons-

(*) - Observações diretas ou através do vastro.

(*) - Paul Roth, comunicação pessoal.

(***) - Informação dos caçadores. 
truído com troncos de Euterpe precatoria. Nestas armadilhas os primatas são considerados a melhor isca para atração dos "gatos . Para a caça de outras espécies, eles também se utilizam de um pequeno cordão de envira ou cipó preso ao gatilho da cartucheira e colocado no caminho por onde o animal está passandc, nas proximidades do barreiro ou da árvore em frutificação. Estas armadilhas são também preparadas nas "veredas", que são caminhos por onde os tatus (Dasypus sp.) e as pacas (Agouti paca) passam com certa freqüência. O caçador distingue se a vereda é do tatu ou paca porque as que são feitas pelos primeiros são mais limpas e de acordo com a largura ele pode determinar qual espécie de tatu (Dasypus sp.) que está passando na triTha.
A caça de excursão é a maneira mais usada para caçar. O percurso pode ser feito a pé ou de canoa. Quando a caçada vai ser realizada nas matas de terra firme, o caçador percorre normalmente uma trilha pré-existente provavelmente de seringueiro ou para extração de óleo de copaíba, numa velocidade média de 1 a $1,5 \mathrm{~km}$ por hora, e esta trilha termina geralmente em um igarapé ou em um barreiro. Os caçadores entram na mata logo após o amanhecer e é comum estarem de volta até as 16 horas. Muitas vezes os caçadores deixam as trilhas quando encontram vestígios de passagem recente de queixadas.

Durante a noite os caçadores podem excursionar no rio Aripuanã, de canoa, utilizando a lanterna para localizar as pacas. E só saem para "paquear" em noites sem luar e na

TABELA 6 - Relação das principais plantas de espera citadas pelos caçadores de Aripuanã

\begin{tabular}{|c|c|c|c|c|c|}
\hline \multirow{2}{*}{ Nome local } & \multirow{2}{*}{ Científico } & \multirow{2}{*}{$\begin{array}{l}\text { Parte da } \\
\text { planta }\end{array}$} & \multirow{2}{*}{$\begin{array}{c}\text { Época de } \\
\text { espera }\end{array}$} & \multicolumn{2}{|c|}{ Animais que freqüentam } \\
\hline & & & & Diurnos & Noturnos \\
\hline Cajá, Taperebá & Spondias lutea & Fruto & Jan-Mar & $\begin{array}{l}\text { Veado, Ceititu, Mutum } \\
\text { Cujubim, Queixada, Co- } \\
\text { tia. }\end{array}$ & Anta, Veado, Paca \\
\hline Piquiá & Cariocar villossum & $\begin{array}{l}\text { Flor } \\
\text { Fruto }\end{array}$ & $\begin{array}{l}\text { Ago-Out } \\
\text { Fev-Abr }\end{array}$ & Cotia & Paca \\
\hline Buriti & Mauritia sp. & Fruto & $?$ & $\begin{array}{l}\text { Veado, Queixada, Cotia } \\
\text { Caititu. }\end{array}$ & Anta, Paca, Veado \\
\hline Uxi & Endopleura uchi & Fruto & Mar-Jun & Queixada, Caititu, Cotia & Anta, Paca \\
\hline Patauá & Jessenia sp. & Fruto & ? & $\begin{array}{l}\text { Queixada, Caititu, Mu- } \\
\text { tum, Cujubim, Jacu }\end{array}$ & Anta, Paca \\
\hline Ucuúba vermelha & Iryanthera grandis & Fruto & Out-Dez & Veado, Cotia. & Pace, Veado \\
\hline Tucumã & Astrocaryum sp. & Fruto & $?$ & Cotia, Queixada, Caititu & Paca \\
\hline Cajui & Anacardium giganteum & Fruto & Jan-Fev & $\begin{array}{l}\text { Cotia, Queixada, Caititu, } \\
\text { Veado, Mutum, Jacu, } \\
\text { Cujubim. }\end{array}$ & Anta, Veado, Paca \\
\hline Tatajuba & Bagassa guianensis & Fruto & $?$ & $\begin{array}{l}\text { Veado, Cotia, Caititu, } \\
\text { Queixada }\end{array}$ & Paca, Veado \\
\hline Pajurá & Parinari sprucei & Fruto & $?$ & Cotia. & Anta, Paca \\
\hline Jenipapo & Genipa americana & Fruto & ? & $\begin{array}{l}\text { Veado, Caititu, Queixa- } \\
\text { da, Cotie. }\end{array}$ & Anta, Veado, Paca \\
\hline Apuí & Ficus $\mathrm{sp}$. & Fruto & Fev-Abr & Veado & Veado \\
\hline Inajá & Maximilliana sp. & Fruto & Ago-Set & Caititu, Veado, Cotia & Veado, Anta, Paca \\
\hline Abio & Pouteria sp. & Fruto & Fev-Abr & $\begin{array}{l}\text { Caititu, Cotia, Mutum } \\
\text { Cujubim, Jacu. }\end{array}$ & Anta, Paca \\
\hline
\end{tabular}


estação seca. É comum nestas excursões abaterem antas e jacarés. Nos meses de julho e agosto, eles podem atirar numa anta durante uma excursão diurna pelo rio, pois nesta época. de acordo com suas informações, as antas correm para o rio para afugentar o grande número de mutucas (Tabanidae) que as perseguem.

Acompanhamos 14 caçadores de excursāo diurna, na terra firme, e o resultado foi positivo para 5 deles. Foram abatidos 1 pato selvagem (Cairina moschata), 3 mutuns (Mitu mitu), 2 queixadas (Tayassu pecari) e 1 coati (Nasua nasua). Pelo método de excursão noturna, de canoa, fizemos 3 tentativas e o resultado foi positivo em 1 oportunidade, com a morte de uma anta.

\section{RENDIMENTO DA CAÇA}

A área de ação dos caçadores foi estimada em $250 \mathrm{~km}^{2}$. Nesta área foram abatidos $90 \%$ dos animais, totalizando $8857,2 \mathrm{~kg}$ nos primeiros 120 dias de 1978 (Tab. 1). Se admitirmos uma perda normal de ossos, cabeça, couro e algumas vísceras de $40 \%$ (White, 1953) teríamos $5314.4 \mathrm{~kg}$ de carne. Admitindo também que o percentual médio de proteína animal é de $20 \%$, assim, teríamos para cada um dos 638 habitantes da comunidade, 14 gramas diárias de proteína animal por dia. De acordo com as recomendações da (WHO (1973), o peso médio da população de Dardanelos foi de $39,65 \mathrm{~kg}$. Esta quantidade de proteína animal diária seria suficiente para preencher 53,8\% das necessidades mínimas de proteína de cada indivíduo. ( $\mathrm{De}$ acordo $\mathrm{cm}$ a recomendação da OMS a quantidade de proteína necessária para a população de Aripuanã é de 0,66 gramas por $\mathrm{kg}$ de peso). O restante, provavelmente seria complementado, com o pescado, o charque $e$ as outras fontes citadas. Se tomarmos a área de ação dos caçadores, teríamos uma rentabilidade de 294,3 gramas de carne de caça por $\mathrm{dia} / \mathrm{km}^{2}$.

As queixadas (Tayassu pecari) representam $69 \%$ dos animais abatidos em peso e, conseqüentemente, a mais importante fonte de proteína animal da caça no alto rio Aripuanã. Obšervamos grupos desta espécie com mais de 80 indivíduos que ao percorrerem as matas deixam um odor característico muito forte por onde passam, facilitando o trabalho do caçador em acompanhá-las. Nāo muito raro, nos meses de setembro e outubro, as queixadas são vistas cruzando o povoado, chegando nes. tas ocasiões e serem abatidos até 20 animais. Provavelmente, os grupos que vivem mais próximos da comunidade foram muito reduzidos nos últimos anos. Em duas oportunidades encontramos grupos com apenas 8 e 4 individuos. Os caititus andam em grupos menores que as queixadas, podendo ser abatidos com o auxílio de um cão que os encurrala nas tocas de tatu canastra (Priodontes giganteus) ou em ocos de árvores caídas.

Também houve um sensível declínio nas populações de Tapirus terrestris e Mazama sp., que há 5 anos eram caçados nas vizinhanças de Dardanelos. Durante o curso do estudo com Chiropotes albinasus apenas em 3 oportunidades encontramos vestígios de pas. sagem de anta na Reserva do INPA em frente ao povoado, numa área de 200 hectares. Atualmente a caça da anta só se realiza quando os caçadores saem por 2 ou 3 dias nos barreiros mais distantes ou excursionando durante a noite no rio Aripuanã e igarapés afluentes.

Como na Amazônia peruana (Castro et al., 1975), o macaco barrigudo (Lagothrix lagothricha) é o mais perseguido entre as 12 espécies de primatas que ocorrem na região. É provável que o peso do animal, o sabor de sua carne e o tamanho dos grupos sejam responsáveis por esta preferência. Encontramos na Reserva Ecológica do INPA grupos de 11-15 individuos, que fazem muito barulho quando estão alimentando-se dos frutos de árvores como o caucho (Castiloa ulei) e cupiúba (Goupia glabra), permitindo ao caçador abater até 3 animais de cada vez. A guariba vermelha (Alouatta seniculus) alcança muitas vezes o peso do macaco barrigudo, são muito procurados na região do baixo e médio rio Aripuanã. onde são mais abundantes. Na região de Dardanelos as populações de guariba são muito baixas e isto pode ser um fator que leva ao aumento de abate de primatas menores como - Chiropotes albinasus, o Cebus albifrons e o Cebus apella. O primeiro é entre estas três espécies o preferido pelos caçadores, pois sua carne quando preparada não deixa o odor característico de certos primatas. Entre os me- 
nores, o Zogue-zogue (Callicebus moloch) é o mais apreciado pelos moradores de Dardanelos. Os caçadores preferem caçar macacos durante o inverno, pois de acordo com suas informações, nesta época os primatas têm mais peso devido ao fato da existência de mais espécies de plantas frutificando. Também, a maioria dos animais pertencentes a esta ordem são abatidos quando $\sigma$ caçador volta sem ter conseguido matar um animal de maior porte. As peles de Lagothrix lagothricha são utilizadas para fabricar cuíca, instrumento usado para a caça da onça pintada, imitando suas vocalizações.

Com relação a avifauna, o mutum (Mitu mituj, representa a espécie que mais contribuiu no fornecimento de carne, que, juntamente com o jacu e o cujubim, são as espécies preferidas pelos habitantes locais. Atualmente é muito difícil observar o mutum nas proximidades de Dardanelos. Entre os Psittacidae, a arara vermelha (Ara macao) é a espécie mais consumida na área.

Dos quelônios, o jaboti (Geochelone sp.) que não aparece na relação (Tab. 1) e o tracajá (Podocnemis unifilis) que provavelmente ocorre somente abaixo do Salto de Dardanelos, são os preferidos como fonte de alimento. Os tracajás são muito perseguidos nos meses de agosto e setembro, quando o rio está muito baixo, época de desova desta espécie nas praias dos rios Branco e Aripuanã.

Existem uma série de fatores culturais que influenciam na caça de determinadas espécies, como o coatá (Ateles paniscus) e a capivara (Hydrochoerus hydrochoeris), que são evitados pela crença de que transmitem doenças da pele. O parauacu (Pithecia monachus) pode causar epilepsia. A carne do tatu canastra (Priodontes giganteus) pode ocasionar espécie de azar porque ele escava no cemitério. Já outros, como a onça parda (Felis concolor), têm em sua carne valor medicinal. Existe uma grande variação entre os indivíduos quanto a essas crenças.

É comum na região as pessoas classificarem a caça guanto a sua capacidade de tirar certas doenças do estado latente (carne remosa). Em Aripuanã, a classificação das car- nes remosas segue aquela descrita por (Smith 1976a) para algumas agrovilas da Rodovia Transamazônica.

\section{DISCUSSÃO E CONCLUSÃ̃o}

Estudo comparativo sobre o padrão nutricional, com amostras de 8 países sul americanos (Lowenstein, 1968) mostra que a qualidsde da dieta era usualmente melhor em grupos oborígenes relativamente isolados, pois estes aprenderam em muitas geraçỏes a fazer um melhor uso da fauna e flora.

Até junho de 1978, em Dardanelos havia um parcial isolamento quanto ao acesso de produtos de primeira necessidade. Este fator foi provavelmente, o maior determinante na quantidade de carne de caça consumida em Dardanelos, juntamente com o potencial de pesca reduzido na região, na área, pelas barreiras naturais do rio Aripuanã.

É possivel que as populações de Tapirus terrestris, Mazama sp., Mitu mitu, Tayassu pecari e o Lagothrix lagothricha tenham decrescido muito nos últimos 5 anos, mas o caboclo amazônico, com base nos seus conhecimentos sobre o comportamento das espécies e suas variações sazonais, diminui o esforço para abater esses animais, utilizando-se de métodos cada vez mais específicos à medida que essas populações tornam-se esparsas. Quando a destruição dos habitats naturais é grande, há uma tendência de serem abatidos animais menores, e eles procuram caçar em locais distantes com menor perturbação.

A orígem da população é um dos fatores que determina a qualidade da caça em termos de espécie. Ross (1978) sugere que em grupos aborígenes, alguns padrões culturais como os tabus alimentares por eles desenvolvidos têm papel importante na manutenção dos estoques das espécies animais com biomassa menor no local. Apesar da orígem da população de Dardanelos ser basicamente amazônica, com a chegada da Rodovia AR-01 e, consequentemente, projetos de colonização, uma série de tabus alimentares serão quebrados pelos colonos oriundos de outras regiōes de país. 
O rendimento da caça está relacionado a fatores como a idade e a experiência do caçador. Apenas 4 individuos foram os responsáveis por quase a metade da caça abatida em janeiro e abril de 1978.

Alguns autores (Meggers, 1971; Gross, 1975) consideram que a dificuldade dos grupos indígenas em conseguirem proteína animal das florestas interfluviais foi um fator limitante no tamanho de suas populações, entretanto, a carne de caça tem sido a base de suporte para muitos grupos estabelecidos na Amazônia. Pierret \& Dourojeanni $(1966,1967)$, em um levantamento com 21 famílias no rio Pachitae e 430 famílias no rio Ucayalli, na Amazônia, estimaram que a caça abatida era suficiente para dar 460 gramas/pessoa/dia e 52 gramas/pessoa/dia, respectivamente. Os resultados do rio Pachitea mostram valores além das necessidades protéicas de um indivíduo e de um local com menos perturbação humana que o rio Ucayalli. Na Rodovia Transamazônica, Smith (1976a) encontrou valores bem inferiores a estes em matas levemente perturbadas. No Aripuanã, para as 114 famílias que compõem a comunidade, a caça seria suficiente para suprir 70 gramas/pessoa/dia, capaz de preencher mais de $50 \%$ das necessidades protéicas de cada indivíduo. Para grupos indígenas, a carne é ainda mais importante (Smith, 1978).

Além da carne de caça ser uma fonte de proteínas importante, ela tem sido destacada também pelos altos teores de minerais, como Ferro e Zinco, cuja deficiência é muito comum na população de Manaus (Shrimpton, 1977: Shrimpton et al., 1978). É provável que a caça, $\mathrm{com}$ finalidades não comerciais que se pratica nos pequenos agrupamentos humanos na amazônia, também possa acarretar riscos para a fauna mais próxima destes povoados, como no caso de Dardanelos.

Qualquer forma de destruição dos ambientes naturais ou restrição a caça de subsistência, resultando numa alteração do padrão alimentar destas comunidades, poderão acarretar sérios problemas sociais. Incentivos a suinocultura e avicultura, juntamente com um programa de domesticação de certas espécies selvagens como o Tayassu pecari e Tayassu tajacu diminuiriam sensivelmente a perseguição a fauna da regiăo.

A pecuária, em fase de especulação na região do município, depois da abertura da rodovia AR-01, com sua disponibilidade baixa de empregos e paralelamente grande atividade de destruição das florestas naturais para a implantação de pastagens, pode resultar numa alteração negativa na dieta da população. É lógico que a criação bovina numa área de 25.000 hectares, correspondente a área de ação onde os caçadores realizam mais de $90 \%$ das caçadas, poderão produzir muito mais proteína animal por unidade de área que a carne de caça, entretanto existem fatores negativos para a criação bovina na amazônia como a estabilidade dos pastos e a conseqüente degradação dos solos com o decorrer dos anos (Falesi, 1976). Esta pobreza dos solos amazônicos tem ocasionado problemas nutricionais para os bovinos, decorrentes da carência de minerais como o sódio, potássio, cobre, manganês e zinco (Sutmöller et al., 1966; Mendes et al., 1978). Estes problemas contribuem para aumentar os preços da carne no mercado, tornando-a mais inacessível para o caboclo amazônico. Não queremos dizer com isto que não se deve criar o gado na amazônia, mas que a pecuária seja feita em solos mais apropriados e em menor escala. Em 1972, segundo o recadastramento do INCRA, a esta atividade se dedicavam pouco mais de $15 \mathrm{mil}$ imóveis com dois milhões de hectares de pastagens e um rebanho de 906 mil cabeças de gado

A Amazônia com seus quase $5.000 .000 \mathrm{~km}^{2}$ não deveria ser apenas considerada como um espaço para empreendimento estranhos a ela, mas talvez, na mais importante fonte de recursos naturais do país.

\section{AGRADECIMENTOS}

Agradecemos ao N. J. Smith pelas sugestões apresentadas no decorrer do trabalho e as críticas ao manuscrito, e ao laboratório de solos da F. C. A. V. de Jaboticabal pelas análises dos barreiros. Os amigos R. Best, C. Bueno, I. Gorayeb. W. Kerr, G. Ranzani, P. Roth, A. Rylands e R. Shrimpton, que fizeram algumas sugestōes valiosas. 


\section{SUMMARY}

The amount of garne killed by hunters in rein forest surrounding Dardanelos (Aripuanã, State of Mato Grosso, Brazil) in southern Amazonia, was recorded from january to april, 1978. White-lipped peccaries (Tayassu pecari), tapirs (Tapirus terrestris), and collared peccaries (Tayassu tajacu), repiesented $89 \%$ of the $8857 \mathrm{~kg}$ of game killed. Wild moat was an important suplementary protein source, and was present in $19 \%$ of the meals. Only four hunters were responsible for over half of the game killed. The demography of the human population, as wel as the local hunting mêthods, are described and the necessity of conservation of wildlife in this region is discussed.

\section{BIBLIOGRAFIA}

ARnaud, E. \& CORTEZ, R.

1976 - Aripuanã: Consideraçōes preliminares. Acta Amazonica, 6(4). Suplemento 11-31.

Castro, N.; Revilla, J. \& Meville, M.

1975 - "Carne de Monte" como una fuente de proteínas en lquitos, con referencia especial a monos. Revista Florestal del Peru. $5(1-2)$.

FALESI, I.C.

1976 - Ecossistema de Pastagem Cultivada na Amazônia Brasileira. EMBRAPA, Boletim Técnico n.0 1, $193 \mathrm{pp}$. Belém-PA.

FrtTkAU, E.J. \& Klince, H.

1973 - On biomass and trophic structure of the Central Amazonian rain forest ecosystem. Biotropica. 5(1): 2-14

Gross, D.

1975 - Protein capture and cultural development in the Amezon basin. American Anthropologist. $77:$ 527-546.

INPA SETOR PEIXE E PESCA

1976 - Estudos ictiológicos do rio Aripuană. Relatório Anual. Págs. 233-234. Manaus-Am.

LOWENSTER, F.

1968 - Some aspects of human ecology in South America. In Biogeography and Ecology in South America. Eds. E.J. Fittkau, J. Illies, H. Klings, G.H. Schabe, H. Sioli, Dr. W. Junk N.V. the Hague. pp. 389-412

Meggers, B.J.

1971 - Amazonia: Man ond Culture in a Counterfeit Paradise. Chịcago: Aldine.

Mendes, M.O.; Conrad, J.H.; Ammerman C.B.; MC DOWELL, L.R. \& L.TTELL, R.C.

1978 - Mineral liver concentrations in cattle affected by age, physiological state and season. Publicação da Comissão Executiva do XI Congresso Internacional de $\mathrm{Nu}$ triçăo. (Resumos Temas Livres), pp. 473.

NAPIER, J.R, \& NAPIER, P.H.

1967 - A handbook of living primates. Academic Press. London and New York.
1976 - As aves on rio Aripuanä, Estados do Mato Grosso e Amazonas. Acta Amazonica. 6(4) Suplemento : 61-85.

Pierret, P.V. \& DourojeanNi, M.J.

1966 - La casa y la alimentación en las riberas del rio Pachitea, Peru. Turrialba 16(3): 271-277.

1967 - Importância de la caza para alimentación humana en el curso inferior del rio Ucayali. Peru. Revista Forestal del Peru. 1(2) pp. 10-21.

PIRES, J.M.

1974 - Tipos de vegetação da Amazônia. Brasil Florestai $5(17)$ : 48-58.

Ross, E. B.

1978 - Food Taboos, diet and hunting strategies: the adaptation to animals in Amazon cultural ecology. Current Anthropology. $9(1): 1-36$.

SHRIMPTON, R.

1977 - Perspectivas das anemias na Amazônia. Trabalho apresentadio no Semináric sobre as anemias nutricionais no Brasil no INAM-MS. Brasília.

Shrimpton, R.; Giugliano, R. \& Giugliano, L.G.

1978 - Preliminary obser ations on chronic human zinc deficiency in Amazonas-Brazil. TrabaIho apresentado no XI Congresso Internacional de Nutriçăo. Rio de Janeiro, September

SMTrH, N.J.H.

1976a - Utilisation of game along Brasil's Transamazon Highway. Acta Amazonica 6(4) : 455-456.

1976b - Spotted ruts and the Amazon skin trade. Oryx, 13(4) : 362-371.

1978 - Human Exploitation of terra firme fauna in Amazonia. Ciência e Cultura. 30(1): 17-23.

SUTMÖller, P.; ABreU, A.V.; GrifF, J. \&

SOMBroEcK, W.G.

1966 - Mineral imbalances in cattle in the Amazon Valley. Communication n. ${ }^{\circ}$ 53. 135 p. Konink Lij Institut Voor de Tropen, Amsterdan.

Weeks, H.P. JR. \& KirPatrick, C.M.

1976 - Adaptations of white-tailed deer to naturally occurring sodium deficiencies. Journal of Wildlife Management. 40(4) :610-625.

WHITE, T.

1953 - A methed of calculating the dietary percentage of various food animals utilized by aboriginal peoples. American Antiquity. $18(4)$ : 396-398.

W.H.O.

1973 - Energy and protein requirements. World Health Organization. Technical report, $522: 1-118$.

(Aceito para publicaçăo em 28/10/78)

Novaes, F.C. 